\title{
Eyelet Device
}

National Cancer Institute

\section{Source}

National Cancer Institute. Eyelet Device. NCI Thesaurus. Code C49946.

A device designed to create a hole in an object for the passage of a cord. 